University of Wollongong

Research Online

Faculty of Business - Papers (Archive)

Faculty of Business and Law

$1-1-2013$

Do satisfied tourists really intend to come back? Three concerns with empirical studies of the link between satisfaction and behavioral intention

Sara Dolnicar

University of Queensland, s.dolnicar@uq.edu.au

Tim Coltman

University of Wollongong, tcoltman@uow.edu.au

Rajeev Sharma

University of Wollongong, rajeev@uow.edu.au

Follow this and additional works at: https://ro.uow.edu.au/buspapers

Part of the Business Commons

Research Online is the open access institutional repository for the University of Wollongong. For further information contact the UOW Library: research-pubs@uow.edu.au 


\title{
Do satisfied tourists really intend to come back? Three concerns with empirical studies of the link between satisfaction and behavioral intention
}

\begin{abstract}
Explaining human behavior is a primary concern for tourism research and a substantial body of research concludes that highly satisfied tourists are more likely to return to a particular destination. In this article, we provide an analysis of this body of work, arriving at three concerns relating to the strength of association between satisfaction and behavioral intention: (1) the link between constructs is complex, resulting in the frequent omission of causal factors; (2) inconsistency with construct operationalization impedes cumulative knowledge development; and (3) explainable variance is impeded by between-study heterogeneity. We illustrate these problems by analyzing empirical guest survey data and conducting a meta-analysis of published papers in the three top tourism journals between 2002 and 2011. We offer four recommendations for future research investigating the link between satisfaction and behavioral intention.
\end{abstract}

\section{Keywords}

satisfaction, between, link, studies, empirical, concerns, three, back, come, intend, really, intention, tourists, behavioral, satisfied, do

\section{Disciplines \\ Business}

\section{Publication Details}

Dolnicar, S., Coltman, T. \& Sharma, R. (2013). Do satisfied tourists really intend to come back? Three concerns with empirical studies of the link between satisfaction and behavioral intention. Journal of Travel Research, 54 (2), 152-178. 


\section{Do satisfied tourists really intend to come back?}

\section{Three concerns with empirical studies}

\section{of the link between satisfaction and behavioral intention}

Sara Dolnicar: School of Tourism, Faculty of Business, Economics and Law, University of Queensland, Brisbane Queensland 4072, Australia, Telephone +61 7336 56702, Fax: +61 7 3346 8716, Email s.dolnicar@uq.edu.au

Tim Coltman: School of Management and Marketing, University of Wollongong, Northfields Ave, Wollongong, NSW 2522, Australia, Telephone: +61 24221 3912, Fax: +61 24221 4170, Email: tcoltman@uow.edu.au

Rajeev Sharma: School of Information Systems and Technology, Faculty of Engineering and Information Sciences, University of Wollongong, Northfields Ave, Wollongong, NSW 2522, Australia, Telephone: +61 24221 3286, Fax: +61 2 4221 4045, Email:

rajeev@uow.edu.au

\section{Acknowledgements}

This research has been supported by the Australian Research Council (ARC) grant program DP130100068 and the Institute for Business and Social Research (IIBSoR) at the University of Wollongong. We thank Magno Queiroz for his assistance with the literature review for this study and Alexander Chapple for general research assistance. The views expressed here are solely those of the authors.

Original submission date: 3 March 2013

Revised submission date: 19 June 2013 


\title{
Do satisfied tourists really intend to come back?
}

\section{Three concerns with empirical studies}

\section{of the link between satisfaction and behavioral intention}

\begin{abstract}
Explaining human behavior is a primary concern for tourism research and a substantial body of research concludes that highly satisfied tourists are more likely to return to a particular destination. In this paper we provide an analysis of this body of work, arriving at three concerns relating to the strength of association between satisfaction and behavioral intention: 1) the link between constructs is complex resulting in the frequent omission of causal factors; 2) inconsistency with construct operationalization impedes cumulative knowledge development; and 3) explainable variance is impeded by between-study heterogeneity. We illustrate these problems by analyzing empirical guest survey data and conducting a metaanalysis of published papers in the three top tourism journals between 2002 and 2011. We offer four recommendations for future research investigating the link between satisfaction and behavioral intention.
\end{abstract}

\section{Key words}

Satisfaction, behavioral intentions, causality, operationalization 


\section{Introduction}

A recurring theme in the service-related literature is the connection between satisfaction and behavioral intention. Satisfaction is a summary cognitive and affective reaction to a prior consumption experience (Rust and Oliver 1994); while behavioral intention refers to the subjective probability that an individual will take a particular action, such as purchasing a product (Fishbein and Ajzen 1975). The central hypothesis is that customers who consider themselves "highly satisfied" with a product or service will be more likely to purchase the product or service again (Bitner 1990; Carr 1999; Rust and Oliver 1994). The significance of these constructs has not escaped practitioners' attention; having been tied to national industry awards (such as the Baldridge Award and the European Quality Award), to paradigms (such as customer value management — see Kordupleski and Simpson 2003) and ideologies (such as “customer delight” — see Oliver et al. 1997).

Understanding how satisfaction during a tourism-related service encounter develops and how it affects behavioral intention to return is therefore, of substantial interest to tourism researchers. New studies seeking to more fully explain when and why the link between satisfaction and behavioral intention, from both conceptual and methodological perspectives, are published every year in the leading tourism journals. These studies unanimously agree that satisfaction leads to favorable behavioral intentions, such as: saying positive things about or even recommending the tourism service to other people; encouraging friends and relatives to visit the tourism service; returning to the destination; and coming back — even if the price were to increase (for example, most recently: Duman and Mattila 2005; Kim and Lee 2011; Lee et al. 2011; Li and Petrick 2008; Petrick 2004; Williams and Soutar 2009; Yuan and Jang 
2007). At the same time, studies suggest that the link is more equivocal and may not hold under certain circumstances (Agustin and Singh 2005; Seiders et al. 2005; Voss et al. 2010).

Tourism research has recently tested the strength of association between behavioral intentions and behavior (McKercher and Tse 2013). In a similar approach we challenge the link between satisfaction and behavioral intention. Specifically, we raise conceptual, measurement and methodological concerns about the validity of the conclusion that a high level of satisfaction will lead to repurchase, and provide some preliminary empirical evidence that these concerns may indeed be justified.

Conceptually, we argue that in the context of tourism services, satisfaction does not necessarily lead to positive behavioral intention, especially with respect to the personal intention to return. Imagine a scenario where a German family visits a lakeside resort in Austria. The family has visited this lakeside resort every year since the children were little, for 12 years now. All members of the family are intimately familiar with the destination and the resort, and they know exactly what to expect. When questions are asked about their level of satisfaction, they will very likely rate it as being only moderately high, because of a lack of positive surprises or a small incident that upset the yearly routine (for example, they did not get their favorite cabin, which they had had for six years running). According to traditional theoretical models of service exchange and customer satisfaction, this family is unlikely to come back next year. But actually the reverse is true: they probably will return, despite technically providing low or moderate satisfaction ratings. A second example involves a cultural tourist who wants to see as many cultural attractions as possible around the world. They may have a sensational experience in Egypt and rate it highly, but will never return, because there are so many other cultural attractions still to explore on the planet. The latter 
perspective supports Kozak et al.'s (2002) claim that one of the certainties in tourism is that many will visit only once.

With respect to measurement, we raise concerns about how construct names and construct operatonalizations vary between studies that investigate the link between satisfaction and behavioral intention. Variation occurs in two ways: 1) constructs with the same name (for example, loyalty) are often operationalized in very different ways; and 2) constructs with different names are often operationalized in the same way. Consequently, it is difficult for a cumulative body of knowledge to develop about the link between satisfaction and behavioral intention.

Our methodological concern is, strictly speaking, also a consequence of the way constructs are measured. For example, when the associations between constructs are measured using the same scale, common methods bias may affect statistical test results. Common method bias refers to the variance that is attributable to the measurement method rather than to the constructs the measures represent (Podsakoff et al. 2003). The most commonly used scale in tourism research is the five- or seven-point Likert scale (Dolnicar 2013, in press). Such scales are particularly prone to capturing response sets. Response sets are specific patterns of how certain respondents use answer options provided to them in surveys. Typical examples include acquiescence or “yea-saying” bias where respondents tend to agree with questions, independent of content, or extreme bias where respondents tend to tick extreme ends of an answer scale, independent of the content of the question. As a consequence of such response sets, the correlation between constructs measures can be either inflated or deflated, leading to incorrect conclusions about the association between them.

The following sections discuss and empirically illustrate the three concerns outlined above. 


\section{CONCERN \#1: Conceptualizing the Link between Satisfaction and Behavioral Intention}

Understanding the determinants of behavior has been a paramount goal for many researchers in tourism, marketing and the broader decision-making sciences. The theory of reasoned action (Fishbein and Ajzen 1975; Ajzen and Fishbein 1980) is a fundamental model for explaining the relationship between attitude and behavior. The model postulates that attitude (that is, an individual's positive or negative evaluation of a consumption experience) and subjective norms (perceived social pressure) will influence the intention to perform an activity, which, in turn, determines actual behavior. The theory is relevant to a wide range of actions, but is also limited, because it assumes individual action is not constrained by external factors (Bagozzi 1992).

The theory of reasoned action has shown remarkable resilience over the years, and several adaptations to the basic model have been made. Examples include the theory of planned behavior (Ajzen 1991) and the theory of trying (Liska 1984). These advances to the basic logic of reasoned action have expanded the domain to include actions subject to interference by internal and external forces. For example, it has been shown that customer satisfaction has a positive effect on attitude change in the post-purchase period (Westbrook and Oliver 1991), and that these positive attitudes enhance repurchase intentions (Yi 1990). The power and versatility of these models has attracted the attention of tourism researchers. For example, tourism researchers have explicitly hypothesized that cognitive and affective evaluations of a prior consumption experience (that is, satisfaction) are followed by a coping response (for 
example, intending to return to a destination) to maintain or increase the level of satisfaction (see for example, Chen and Tsai 2007; Kim and Lee 2011; Petrick 2004; Weaver et al. 2007).

Others are critical of prior work suggesting that the sources cited by tourism researchers are used in a rather selective manner and that "a more thorough review of these works reveals that the authors came to equivocal conclusions about the link” (McKercher and Tse 2013 p.672). For example, several studies suggest that simply satisfying customers may not be sufficient to drive repurchase behavior (Agustin and Singh 2005; Cronin and Taylor 1992; Jones and Sasser 1995; Seiders et al. 2005; Voss et al. 2010). Reichheld’s (1993) study of automobile owners reveals that although $85-90 \%$ of customers were satisfied with the chosen brand, only $40 \%$ repurchased the brand. Automotive firms have often found that achieving satisfied customers will not guarantee higher repurchase, and subsequent work has examined the role of moderators. Similarly, Jones and Sasser’s (1995) pioneering work at Xerox revealed that only those customers that were totally satisfied (that is, those with a score of 5 on a 1-5 satisfaction scale) were six times more likely to repurchase. This finding implies that the right level of customer satisfaction is critical, because, except in rare circumstances, anything less than total satisfaction is insufficient to secure future customer loyalty.

Empirical evidence indicates that complementary and substitute effects may explain why moderately satisfied customers repurchase at a different rate to highly satisfied customers (Voss et al. 2010). For example, “customer, relational and marketplace characteristics complement satisfaction in weak-satiation purchase categories and substitute for satisfaction in strong-satiation purchase categories” (Voss et al. 2010, p.121). In their study individual satiation is defined as a temporary reduction or cessation of consumptive behavior (Assael 
2003) such as when a person's desire for physical activity is lower after they have walked the Kakoda track.

Intentions are subject to temporal effects that are especially prescient under conditions when purchases are infrequent, such as travel. Aasaker, Vinzi, and O’Connor (2011) evaluated the intent to revisit across three temporal dimensions (immediate, midterm, and long term) and found an inverse relationship between time frame and intent to repurchase. The multiplicity of tourist destinations available to travelers can cause one time only visits (Kozak et al. 2002). In a study of Japanese and American tourists visiting Hawaii, Caneem (2003) found that culture influences intent to return. The study found that Americans with a low intention to return score had a high return rate, while Japanese tourists that expressed a high intention to return had a low repeat visitation rate. Thus, the link between satisfaction and behavioral intention is complex, and implies that there are a number of possible reasons why high levels of satisfaction do not always lead to the expected positive behavioral intention.

To illustrate the complex link between satisfaction and behavioral intention we provide results of an analysis from an Austrian guest survey data set which is part of a regular data collection exercise conducted by the Austrian National Tourism Organization (descriptions of the methodology are available in Dolnicar and Leisch (2003) as well as on http://www.tourmis.info where some of the data can also be downloaded at no cost). Guests visiting Austria were asked about their satisfaction with the service encounter and their intention to return to the destination. Results of the cross-tabulation of satisfaction and stated intention to return are provided in Table 1 . What we would expect to see in such a crosstabulation is that guests who were highly satisfied (or whose expectations were exceeded) had by far the highest intention to return. However, the results imply that this is not the case. 
Among the guests with the highest satisfaction levels only $24 \%$ stated that they would almost certainly return to the destination, $35 \%$ said they probably would and $41 \%$ said it was unlikely. Of those whose expectations were (merely) met, 30\% said that they would almost certainly return.

Please insert Table 1 here

The percentage of those whose expectations were met (but not exceeded) and who state that they will almost certainly return (30 per cent) is higher than the percentage of those whose expectations were not met (14 per cent, which is not surprising and in line with the common belief of the association between satisfaction and intention to return) as well as higher than the percentage of those whose expectations were superseded (24 per cent). The latter insight is surprising and would not be expected under the current ruling assumption that satisfaction is positively associated with the intention to return. Rather, under this assumption, we would expect highly satisfied tourists to have a significantly higher stated intention to return.

The higher intention to return score for tourists whose expectations were merely met may be due to these tourists having more experience with the destination, possibly being loyal, repeat customers. This familiarity with the destination may make it difficult for their expectations to be superseded. Support for this proposition is provided by the fact that $60 \%$ of those who visited the destination twice or more said that they would almost certainly return, irrespective of their satisfaction level; whereas only $12 \%$ of those who visited for the first time said they 
would return. In this particular case, having visited before is a substantially better predictor of intention to return than satisfaction. The results from this study suggest that satisfaction may be only one of many factors affecting the intention to return.

To investigate whether this statement is warranted we run a binary logistic regression. The dependent variable is the intention to return. We include the answer options "almost certain” and "probably” because we wish to test the central hypothesis that highly satisfied customers will be more likely to repurchase (Bitner 1990; Carr 1999; Rust and Oliver 1994).The independent variables are satisfaction (with the three answer options "was better than expected”, "met my expectations” and "did not meet my expectations”), how often the destination has been visited before (never, once or more than once) and a set of travel motives (which were elicited from respondents by asking them to state for each of the listed motives, whether this was an important motive for visiting Austria on this particular vacation or not). All travel motives which were included in the survey were also included in the analysis; no selection took place. The a priori probability of guessing correctly if any given tourists intends to return or not is $51 \%$. If the independent variables listed above are used the model is able to predict the intention to return for $70 \%$ of the respondents correctly. The coefficients are provided in Table 2 and sorted by the coefficient $\beta$ which indicates the strength of the influence of each variable. As can be seen, having visited the destination before contributes most to the explanation of intention to return. A number of the travel motives also contribute to explaining intention to return, specifically: cultural tourism and wanting entertainment affect positively the intention to return, whereas high importance of socializing, resting and relaxing and coziness have a negative association. Most interestingly, the effect of satisfaction is insignificant, it does not contribute to improving the prediction of 
whether any given tourists at the destination has a high intention to return $(\beta=-0.152, \mathrm{p}=$ $0.065)$.

Please insert Table 2 here

It can be concluded from the analysis of the 1994 Austrian guest survey data that a wide range of factors affects tourists' intention to return and that satisfaction may play only a minor role in this context. Thus, the link between customer satisfaction and behavioral intention may be more complex than the model of reasoned action (Fishbein and Ajzen 1975) and the variants to this model (Ajzen 1991; Liska 1984) predict. In cases where models linking satisfaction with behavioral intentions are insufficiently conceptualized, tourism researchers are at risk of drawing incorrect conclusions about the link between satisfaction and behavioral intention. 


\section{CONCERN \#2: Measuring the Link between Satisfaction and Behavioral Intention}

Estimating customer satisfaction and behavioral intention models at the individual level poses many challenges. For example, whether measures of satisfaction should be based on a customer's current product or service experience, or if satisfaction should be evaluated with respect to competing alternatives such as that offered by paired comparison or relative importance approaches (see for example, Marley and Louviere 2005). While the latter approach has become popular, it remains inappropriate whenever a customer is unfamiliar with alternative competitive offerings. In the field of customer satisfaction, researchers have measured the dependent variable based on post-purchase measures such as attitude change, repeat purchase, positive word-of-mouth intentions and brand loyalty (Oliver 1993; Soderlund and Ohman 2003). Yet scholars outside this field of research in psychology and philosophy argue that several different intention constructs exist and that they produce quite different associations with one another (Fishbein and Stasson 1990). Soderlund and Ohman (2003) argue that satisfaction researchers have paid too much attention to aspects of satisfaction and not enough to different theoretical intention constructs. Additionally, multicollinearity can be a significant problem in attitudinal models (Rust and Oliver 1994) and the types of survey instruments commonly used to measure satisfaction may lead to abnormal and noisy distributions due to unobservable factors.

In order to investigate these measurement concerns in the context of tourism literature, we reviewed in detail the measures used in 38 studies recently published in the top three international tourism journals (Journal of Travel Research, Annals of Tourism Research and 
Tourism Management — the full list of references as well as tables specifying for each study which measures were used for which construct are available in the online supplementary materials). Results reveal that a wide range of satisfaction measures are used in tourism research, and many are based on the measures put forward by Oliver (1997) or Spreng et al. (1996). Their measure is one of overall satisfaction and aims to obtain an overall evaluation of a specific service experience. It is designed to capture two dimensions postulated by Swan and Oliver (1989): valence (the nature of the evaluation of the specific service) and intensity (the strength with which the evaluation is perceived). The measure used by Spreng et al. consists of four items (“very satisfied/very dissatisfied”, "very pleased/very displeased”, “contented/frustrated” and “delighted/terrible”), each of which is answered using a sevenpoint answer format. Several studies have developed their own measure of overall satisfaction. For example, Weaver et al. (2007) and Yuan and Jang (2007) asked respondents directly about their overall satisfaction with the tourism services under study, offering them seven answer options that ranged from "very dissatisfied” to "very satisfied”.

Two key observations emerge from the review of satisfaction measures currently used in academic tourism research:

1. Measures of satisfaction differ substantially in meaning. For example, one would expect the single-item measure asking about satisfaction with the service to lead to results different from the four-item measure proposed by Spreng et al. (1996) that incorporates additional constructs, namely: feeling pleased or displeased; feeling contented or frustrated; and feeling delighted or terrible. Also, the fact that these four items represent two dimensions is ignored by adding the responses to all four items to one overall value of satisfaction. 
2. Some measures of satisfaction do not appear to capture satisfaction, but instead refer to related, although distinctly different constructs. For example, the perceptions of the value for money construct in tourism (Yuan and Jang 2007) is a different construct from satisfaction; a person may be highly satisfied with a tourism experience, yet perceive that it was not particularly good value for money (for example, an expensive admission to a theme park). Alternatively, a person may feel that an experience was extremely good value for money, but they are not satisfied with the experience (for example, a free tour of the allergy garden describing various plants and possible allergies to these plants). Similarly, the question "This is one of the best theme parks I could have visited” (Bigne et al. 2005) may not actually reflect satisfaction, but is rather an objective assessment that the theme park visited is the best (although it really was not much fun to spend the day there). It may even be an expression of cognitive dissonance (Festinger et al. 1956) that attempts to make the visitor feel better about the high admission fee.

This implies that studies in tourism investigating the link between satisfaction and behavioral intention are not necessarily studying the same construct, even though they use the same label name for it, as illustrated in Figure 1 using actual measures taken from the articles we reviewed for the present study (details on the measures are available in the online supplementary materials). This makes it difficult for cumulative knowledge to develop, and it puts great pressure on readers and users of the studies to try to determine exactly what conclusions can actually be drawn. 
The measure of behavioral intention differs from the satisfaction measure because, unless it states specific intended behavior, it can validly contain a wide range of behaviors. Tourism researchers who have studied the link between satisfaction and behavioral intention in recent years most frequently cite Zeithaml et al. (1996) when explaining their measure; Zeithaml et al. used a 13-item measure that included behaviors in four distinctly different areas: word-ofmouth communications, purchase intention, price sensitivity and complaining behavior. They asked respondents to answer these questions using a seven-point likelihood scale with the endpoints labeled "not at all likely” and "extremely likely”. Only in one of the reviewed tourism studies was the original scale used (Kim and Lee 2011). In other instances, variations were used that are often not explained or justified. For example, five-point Likert scales are used instead of likelihood scales, and only selected items labeled in conceptually different ways to the original scales developed are used. Several authors use self-developed items to measure behavioral intention. For example, Yuan and Jang (2007) ask respondents about their likelihood of buying local wines and visiting local wineries; Weaver et al. (2007) ask respondents how likely they are to visit Hong Kong for pleasure travel. In both studies respondents were offered a seven-point likelihood scale.

It can be concluded that deriving firm conclusions on the satisfaction-behavioral intention link is difficult, because of the wide variety of different measures used. 


\section{CONCERN \#3: Analyzing the Variance in the Link between Satisfaction and Behavioral Intention}

Studies by Sharma and colleagues $(2001 ; 2007 ; 2009)$ show that the nature of the scale used to capture responses can affect the magnitude of the associations. For example, if respondents are asked to assess both satisfaction and intention to return on a seven-point Likert scale and they have a tendency to use the extreme positive end of the scale, then the association between the two constructs will be overestimated in any statistical test because the test does not discriminate between response bias and the content of a respondents' answer.

To assess whether the body of work investigating the link between satisfaction and behavioral intention in tourism is at risk of response style bias, we first conducted a metaanalysis to determine the strength of association between satisfaction and favorable behavioral intentions. For the meta-analysis we reviewed articles published in Annals of Tourism Research, Journal of Travel Research and Tourism Management between 2002 and 2011. Twenty-five empirical studies that included both satisfaction and behavioral intention were included. Studies which included more than one sample or more than one measure of satisfaction or intention are represented by more than one data point, resulting in a final sample of 38 data points. The reported correlations between satisfaction and behavioral intention range from 0.02 to 0.88 , with the sample size varying from 169 to 6,172.

By conducting a meta-analysis of the correlations between satisfaction and behavioral intention we could estimate the central tendency as well as the variability of the cumulative empirical evidence within a certain research domain (Hunter and Schmidt 1990; Glass et al. 1981; Wolf 1986; Sharma and Yetton 2003). As such, it serves two key purposes: 1) it 
enables the testing of theories based on a systematic synthesis of the cumulative empirical evidence, rather than on the evidence from a single study or from a few selected studies, and 2) it enables the testing of theoretical and methodological moderators that are not easily tested within individual studies. In particular, we employed meta-analysis to test the moderating effect of methods of measuring predictor and criterion variables (Sharma et al. 2009; Sharma and Yetton 2001). We follow Sharma et al. (2007; 2009) to employ metaanalysis-based techniques to estimate the effect of common method bias within the theoretical domain of the theory of reasoned action.

Our analysis follows the protocols for random-effects meta-analysis recommended by Borenstein et al. (2009) and Schmidt et al. (2009). The random-effects model has recently supplanted the previously popular fixed-effect model described by Hunter and Schmidt (1990). This is because of the understanding that it is both theoretically and empirically more justifiable to assume that the studies in a meta-analysis are drawn from a heterogeneous population. The fixed-effect model assumes that all studies share a common "true" correlation, while the random-effects model allows for the "true" correlation to vary across studies (Borenstein et al. 2009; Sharma and Yetton 2011).

The meta-analysis results based on the random-effects model returned a mean correlation across all 38 data points of 0.59 , with a $95 \%$ confidence interval of 0.51 to 0.65 (see Table 3 ). Results from the fixed-effect model are also reported for comparison purposes. As expected, the random-effects model estimates a wider 95\% confidence interval than the fixed-effect model, with a mean of 0.63 and interval of 0.62 to 0.63 . 
Please insert Table 3 here

Table 4 reports the test of between-study heterogeneity that estimates the likelihood that the studies in the meta-analysis are drawn from a homogeneous population or whether the underlying “true” correlations across the studies are heterogeneous (Borenstein et al. 2009). A significant Q-value indicates that there is a greater excess heterogeneity in the correlations between studies than can be explained by sampling error. The results in Table $4(\mathrm{Q}=2,094.4$, $\mathrm{p}<0.05$ ) indicate that significant heterogeneity exists across studies. The I-squared statistic estimates the proportion of variability in correlations across studies not explained by sampling error. Table 4 reports that $98 \%$ of the variability in correlations across studies is unexplained. This is consistent with the range of correlation values observed across the studies; recall that the reported correlations vary between 0.02 and 0.88 . Tau-squared value $\left(\tau^{2}=0.11\right)$ estimates the population variance (standard deviation) of the correlation between satisfaction and behavioral intention. The 95\% credibility interval of the correlation between satisfaction and behavioral intention is estimated to be effectively between 0 and 1 . The $95 \%$ confidence interval reported in Table 3 reflects the precision of the estimate of the mean correlation, while the 95\% credibility interval reflects the variability in the "true" correlations across the population of studies.

Please insert Table 4 here

Do satisfied tourists really intend to come back? page 18 of 46 
The test of between-study heterogeneity (Table 4) suggests that the studies are drawn from extremely heterogeneous populations and that a search for moderators to explain the between studies variation in correlations is justified. From a theoretical perspective, this implies that other unmeasured variables exist that influence the correlation between satisfaction and behavioral intention.

In order to better explain the variance in the correlations between satisfaction and behavioral intention we investigated the effect of two potential methodological moderators: the type of dependent variable employed and the type of independent variable employed. To investigate the effect of the type of dependent variable employed, we reviewed the operationalization of the dependent variable across the studies. The dependent variable was labeled: "behavioral intention” in 12 data points; “intention” (or a variant, for example, intention to revisit) in 11 data points; "loyalty" (or a close variant, for example, "brand loyalty") in 11 data points; and “word of mouth” in three data points. In one data point "search for alternatives” could not be categorized (see Appendix 2 for a complete listing). Intention and behavioral intention may represent a completely different construct from that captured by loyalty; also, the correlations between intention/behavioral intention and satisfaction may capture a totally different phenomenon than that captured by the correlation between loyalty and satisfaction.

We conducted a meta-analysis to test the moderating effect of type of dependent variable. Variables labeled as intention or behavioral intention were coded as $1(n=23)$, while those labeled as loyalty were coded as $2(n=11)$. All others were coded as 3 . A test of differences in means was not significant ( $p>0.05$; see Table 5) suggesting that the type of dependent variable employed does not explain the variation in correlations across studies. 
Please insert Table 5 here

We also conducted a similar test to test for the moderating effect of the operationalization of the independent variable. The independent variable was labeled: “customer satisfaction” (or customer, visitor or tourist satisfaction) in nine cases; “overall satisfaction” in five cases; "recovery satisfaction” in two cases; and "satisfaction” in 21 cases. One data point could not be categorized. Variables labeled as "satisfaction" or a variant thereof were compared against all other labels (Table 6). The mean difference was not significant ( $p>0.05)$, suggesting that the variance in correlations across studies is not explained by the type of independent variable employed.

Please insert Table 6 here

To determine why the operationalizations of the dependent and independent variables do not explain the variability in observed correlations, we closely reviewed the items employed to operationalize the constructs. Our review revealed some interesting patterns. Drawing on the Zeithaml et al. (1996) scale, we found items reflecting three distinct areas: word-of-mouth communications, purchase intentions and price sensitivity. However, irrespective of whether the dependent variables were labeled “intention/behavioral intention” or "loyalty”, studies employed various combinations of the above three areas (see Table 7), confirming concern \#2 
which relates to the measurement of the dependent and independent variables. For example, typical measures for behavioral intention include "Say positive things to other people”, “Recommend to other people”, “Encourage friends”, and “I would choose again”. Typical measures for intention include "Recommend to others”, "I would choose again”, "Interested in returning” and "Say positive things to others". Typical measures for loyalty include “Intention to return”, “Recommend to others”, "Likelihood of return”, and "Say positive things to other people”. Typical measures for word-of-mouth reputation include "Would positively recommend to other people" and "I would tell other people positive things about this hotel”. Table 7 reports the frequencies with which the different labels employed one or more of the above four areas. Given the pattern in Table 7, distinguishing between the operationalizations of loyalty and those of intention/behavioral intention is not possible. Thus, unsurprisingly, the mean correlations across the different dependent variable labels are not significantly different, as reported in Table 5.

Please insert Table 7 here

Our review of how the independent variable had been operationalized also revealed similar patterns (see Table 8): the variations in the name of the satisfaction variable were not reflected in the variation in items employed to operationalize them. Typical items for consumer/customer/visitor/tourist satisfaction include "I am satisfied with the service” and "I am pleased to have visited”. Typical measures for overall satisfaction include "Level of Satisfaction” (measured on Likert-scale or semantic differential scale). Typical measures for 
satisfaction include “Overall I am satisfied”, “I am satisfied with the service”, "I am happy with my decision”, “Level of satisfaction” and “Overall quality of experience”.

Please insert Table 8 here

The final outcome of the meta-analysis is that, based on the recent body of work investigating the link between satisfaction and behavioral intention in tourism, the best estimate of the correlation between satisfaction and intention is 0.59 (Table 3). Furthermore, high variability exists in the correlation, suggesting strong heterogeneity across studies (Table 4). Finally, the operationalizations of the dependent variable or the independent variable are not a source of heterogeneity (Tables 5 and 6). Rather, we found that researchers chose to employ different label names, but then used similar sets of items to measure the constructs (Tables 7 and 8).

Based on the findings of the above meta-analysis, we now speculate on the extent to which method bias could affect the findings reported in the field of tourism. An analysis of method bias requires variability in the manner in which the constructs have been operationalized across studies. However, as reported in Appendices 2 and 3, all studies employ the Likert scale to measure the independent variable (satisfaction) and the dependent variable (intention and/or loyalty). Given the absence of variability in methods across studies, it is not possible to directly conduct an analysis of the effect of method on the findings. Nevertheless, the findings in Sharma et al. (2009) offer a good point of comparison for this specific data situation. Sharma et al. meta-analyzed the findings of 75 studies based on the theory of reasoned action/theory of planned behavior and found that the method employed to capture 
behavior explained 56\% of the variance in the correlations between attitude and behavior across studies. Specifically, the methods employed in their meta-analysis varied across four categories: archival reports of behavior, self-reported behavior captured on open-ended scales, self-reported behavior captured on Likert-type scales with behavioral anchors and Likert-type scales with affectual anchors.

In the meta-analysis by Sharma et al. (2009) the best estimate of the correlation when both constructs are measured on affectual Likert scales is 0.59 - almost identical to that estimated for the tourism studies under investigation. For this situation, Sharma et al. (2009) estimate that almost all of this correlation is in fact due to method bias. Controlling for method bias, they estimate that the correlation between attitude and behavior is non-significant. The metaanalytic estimate of the observed correlation between satisfaction and intention obtained in this study is also 0.59. Given the authors' prior estimate of the extent of bias when both the independent and dependent variables are measured on Likert scales, the strength of the relationship between satisfaction and intention needs to be interpreted with extreme caution. It is possible that it too could be entirely attributable to method bias.

Note also that the results from the illustrative example using the Austrian guest survey dataset presented earlier are consistent with the above conclusion. The results reported in Table 2 show that satisfaction has a non-significant effect on intention to return for visitors. 


\section{Conclusion and Recommendations}

Tourism academics have shown great interest in understanding the association between satisfaction and behavioral intention. Consequently, a substantial body of work has developed that investigates and reinvestigates this link, leading to the common belief that high levels of tourist satisfaction lead to higher intentions of these tourists to behave in ways that are beneficial to the tourism provider, such as recommending the service to friends, having future repurchase intentions or being less sensitive to paying a price premium. The primary association between satisfaction — which translates into the practical concern regarding whether customers will return to a company or recommend it to others — underpins the significant investment by tourist providers in marketing programs.

This paper examines the body of work from different perspectives and assesses whether tourism researchers are at risk of producing systematically biased results. Conceptual, measurement and methodological perspectives are considered. First, the conceptual perspective relates to how the nature of the relationship between satisfaction and behavioral intention is conceptualized. Our investigations show that certain valid concerns exist, due to oversimplified conceptualizations of the association, possibly ignoring other key factors which may in fact be the true reason for the variation in behavioral intention. Second, through taking a measurement perspective, we identify substantial variability of definitions and variability and overlap of operationalizations of both the construct of satisfaction and the behavioral intention constructs, making it difficult to derive cumulative knowledge about the link between satisfaction and behavioral intention. Third, a methodological perspective forces us to question the popularity of multi-category scales in empirical tourism research. Specific 
concerns about common method bias affecting the results of studies investigating the link between satisfaction and behavioral intention are raised. Based on the meta-analysis conducted for recent tourism studies, and based on evidence from studies estimating common method bias in similar data situations, we conclude that the risk is extremely high that prior research results investigating the link between satisfaction and behavioral intention are affected by response bias.

Our study allows us to derive a number of simple recommendations which can help to minimize the risk of bias in studies investigating the link between satisfaction and behavioral intention link in the future:

\section{Recommendation 1: Model conceptualization}

Before any kind of data analysis is conducted, the researcher should familiarize themselves with the literature and work with tourism industry representatives to conceptually derive the hypothesized variables affecting behavioral intention. Only after such work is undertaken should empirical data be collected and analyzed. While models based on the theory of reasoned action/theory of planned behavior have shown a good ability to predict intention (even though validity threats arising from method bias remain to be addressed), it is not clear what implications the models have for practice. In particular, those models do not include any managerial interventions as antecedents of attitude or satisfaction, hence, no valid implications can be drawn from such studies regarding managerial interventions that organizations can undertake in order to increase revisit behavior. Researchers should make their research relevant for practice by including variables that are relevant for managers in specific tourism contexts, for example: are the kinds of tourists visiting the destination 
potential repeat visitors or is visiting the destination a once in a life-time experience, can vacation activities be offered that could give tourists a reason to return to the destination etc.

\section{Recommendation 2: Construct definition and operationalization}

All constructs should be unambiguously defined, and the measures used in the empirical study should be provided to enable any user of the study to assess whether the survey question actually measures what it is conceptually meant to measure. A precise conceptual definition is essential because it then serves as the central referent to the construct operationalization from which scholars can assess content validity. It would be particularly valuable if the measures could be contrasted to prior work in the area. This would ensure that the measures used are clear to readers of the research and provide justification for whether similar findings could be expected or not.

\section{Recommendation 3: Selection of suitable and different answer formats}

Constructs should be measured using appropriate answer options that allow respondents to express their level of satisfaction as well as their behavioral intention. Preferably, the answer formats should be different, in order to avoid common method bias inflating correlations. Behavioral intention, for example, could be measured using an 11-point probability scale designed to estimate future behavior (commonly termed the Juster scale). The forced choice binary format has also been shown to be well suited for measurement of behavioral intentions (Dolnicar and Grün 2009). Satisfaction can be measured using a range of different scales based on a customer's current product or service experience, or their level of satisfaction with respect to competing alternatives. Therefore, there is no reason, based on both prior 
theoretical recommendations and empirical findings, that the dependent and independent variables in studies investigating the relationship between satisfaction and behavioral intention should be measured using the same answer scale, as is currently predominantly the case in tourism survey studies.

An important limitation to varying answer formats is that, while it is possible to capture behavior in many formats, cognitions such as intention and satisfaction can only be captured in formats that are susceptible to high method bias. However, surprisingly, most studies focus on intention as the dependent variable, and very few studies attempt to employ behavior as the dependent variable. While it is understandable that revisit behavior is difficult to research, other variables employed to operationalize intention or loyalty could be captured as behaviors, rather than intentions. For instance, word-of-mouth communications could be captured as behavior, by employing items such as "How many times in the last month did you mention [the destination] positively to other people?" or "How many times did you post a positive message about [the destination] on social media?” Responses to such questions could be captured on open-ended scales. This could not only reduce the magnitude of method bias, on account of employing Likert scales for both variables, but also the different answer formats employed across studies could enable researchers to estimate the magnitude of method bias. Further, it may make the research more relevant for practice, because managers are likely to be more interested in actual behaviors, rather than intentions. Other possible approaches would be to survey people who have returned to the same destination, ensuring that the actual behavior of interest has occurred, and asking them about their satisfaction with their last vacation at this destination. While this approach relies on remembering past satisfaction, it does not a priori imply that this past recollection of satisfaction will be biased. In fact, it may well be that a more accurate assessment can be made after some time has 
passed so that an overall average of the experience can be formed. Temporal sequencing effects have been used to explain how satisfaction with a product (good or service) is expressed (Oliver 1980) and any assessment of satisfaction immediately after (end state effect) or even during the vacation (salient or peak effect) may be affected disproportionately by the occurrence of isolated incidents, positive or negative. Miron-Shatz (2009) found that when respondents are asked to evaluate multi episode events (such as a tourism encounter) that simple averages better explain their overall evaluations than sequence effects (such as an end state perceptions).

\section{Recommendation 4: Reporting}

Meta-analyses offer great potential for contrasting and comparing results from published studies. This enables scholars to summarize the state-of-the-art cumulative knowledge in a field such as tourism research. This technique, however, relies upon authors providing all the information required for conducting a meta-analysis in their study. The following pieces of information should be provided: 1) the complete correlation matrix, including all dependent, independent and control variables; 2) the questionnaire items for all constructs as presented to the respondents; 3) details of scales and anchors for each questionnaire item; and 4) as much description of the sample, study context and other details of the research setting as is available.

In sum, we conclude from this study that the focus of past studies investigating the association between satisfaction and behavioral intentions, are at high risk of being biased and, consequently, having led to misleading conclusions about the nature of the satisfactionbehavioral intention link. It is therefore critical to (1) interpret findings from past research 
with caution, paying specific attention to conceptual, measurement and methodological aspects of the studies, and to (2) design future studies with the dangers of potential bias in mind. 


\section{References}

Aasaker, G., V. Esposito Vinzi, and P. O’Connor (2011). “Examining the Effect of Novelty Seeking, Satisfaction, and Destination Image on Tourist’s Return Pattern: A Two Factor, Non-Linear Latent growth Model.” Tourism Management, 32: 890-901.

Agustin, C., and J. Singh (2005). “Curvilinear Effects of Consumer Loyalty Determinants in Relational Exchanges.” Journal of Marketing Research, 42 (2): 96-108.

Assael, H. (2003). Consumer Behavior: A Strategic Approach. Boston: Houghton Mifflin.

Azjen, I. (1991). “The theory of planned behavior.” Organizational Behavior and Human Decision Processes, 50 (2): 179-211.

Azjen, I., and M. Fishbein (1980). Understanding attitudes and predicting social behavior. Englewood Cliffs, N.J: Prentice-Hall.

Bagozzi, R. P. (1992). “The Self-Regulation of Attitudes, Intentions, and Behavior.” Social Psychology Quarterly, 55 (2): 178-204.

Bigne, J. E., L. Andreu, and J. Gnoth (2005). “The theme park experience: An analysis of pleasure, arousal and satisfaction.” Tourism Management, 26 (6): 833-44.

Bitner, M. J. (1990). “Evaluating Service Encounters: The Effect of Physical Surroundings and Employee Responses.” Journal of Marketing, 54 (April): 69-82.

Borenstein, M., L. V. Hedges, J. P. T. Higgins, and H. R. Rothstein (2009). Introduction to Meta-Analysis. West Sussex, UK: Wiley. 
Caneem, J. (2003). “Cultural Determinants of Tourist Intention to Return.” Tourism Analysis, 8 (3): 237-42.

Carr, N. G. (1999). “Marketing: The Economics of Customer Satisfaction.” Harvard Business Review, 77 (2): 15-16.

Chen, C-F., and D. C. Tsai (2007). “How Destination Image Evaluative Factors Affect Behavioral Intentions?” Tourism Management, 28: 1115-22.

Cronin, J. J., and S. A. Taylor (1992). “Measuring Service Quality: A Reexamination and Extension.” Journal of Marketing, 56 (3): 55-68.

Dolnicar, S. (2013, in press). “Asking Good Survey Questions.” Journal of Travel Research.

Dolnicar, S., and B. Grün (2009). "Does One Size Fit All? The Suitability of Answer Formats for Different Constructs Measured.” Australasian Marketing Journal, 17 (1): 58-64.

Dolnicar, S., and F. Leisch (2003). "Winter Tourist Segments in Austria - Identifying Stable Vacation Styles for Target Marketing Action.” Journal of Travel Research, 41 (3): 28192.

Duman, T., and A. S. Mattila (2005). "The role of affective factors on perceived cruise vacation value.” Tourism Management, 26 (3): 311-23.

Festinger, L., H. W. Riecken, and S. Schachter (1956). When Prophecy Fails: A Social and Psychological Study of a Modern Group that Predicted the Destruction of the World. Minnesota: University of Minnesota Press. 
Fishbein, M., and I. Azjen (1975). Belief, attitude, intention, and behavior: an introduction to theory and research. Reading, Mass: Addison-Wesley.

Fishbein, M., and M. Stasson (1990). “The Role of Desires, Self-Predictions, and Perceived Control in the Prediction of Training Session Attendance.” Journal of Applied Psychology, 20 (3): 173-98.

Glass, G. V., B. Mcgaw, and M. L. Smith (1981). Meta-Analysis in Social Research. Beverly Hills, CA: Sage.

Hunter, J. E., and F. Schmidt (1990). Methods of Meta-Analysis: Correcting Error and Bias in Research Findings. Newbury Park, CA: Sage.

Jones, T. O., and W. E. Jr. Sasser (1995). “Why Satisfied Customers Defect.” Harvard Business review, 11/12: 88-99.

Kim, Y. K., and H. R Lee (2011). “Customer satisfaction using low cost carriers.” Tourism Management, 32 (2): 235-43.

Kordupleski, R., and J. Simpson (2003). Mastering Customer Value Management: The Art and Science of Creating Competitive Advantage. Cincinnati: Pinnaflex Educational Resources Inc.

Kozak, M., T. Huan, and J. Beaman (2002). “A Systematic Approach to Non-Repeat and Repeat Travel.” Journal of Travel and Tourism Marketing, 12 (2): 19-38.

Lee, J-S., C-K. Lee, and Y. Choi (2011). “Examining the Role of Emotional and Functional Values in Festival Evaluation.” Journal of Travel Research, 50 (6): 685-96. 
Li, X., and J. F. Petrick (2008). "Examining the Antecedents of Brand Loyalty from an Investment Model Perspective.” Journal of Travel Research, 47 (1): 25-34.

Liska, A. E. (1984). “A Critical Examination of the Causal Structure of the Fishbein/Ajzen Attitude-Behavior Model.” Social Psychology Quarterly, 47 (1): 61-74.

Marley, A., and J. Louviere (2005). "Some Probabilistic Models of Best, Worst, and BestWorst Choices.” Journal of Mathematical Psychology, 49 (6): 464-80.

McKercher, B., and T. S. M. Tse (2013). "Is Intention to Return a Valid Proxy for Actual Repeat Visitation?” Journal of Travel Research, 51 (6): 671-86.

Miron-Shatz, T. 2009. "Evaluating multiepisode events: boundary conditions for the peakend rule.” Emotion, 9 (2): 206.

Oliver, R. L. (1980). “A cognitive model of the antecedents and consequences of satisfaction decisions.” Journal of Marketing Research 17 (4), 460-9.

Oliver, R. L. (1993). “Cognitive, Affective, and Attribute Bases of the Satisfaction Response.” The Journal of Consumer Research, 20 (3): 418-30.

Oliver, R. L. (1997). Satisfaction: a behavioral perspective on the consumer. New York: McGraw Hill.

Oliver, R. L., R. T. Rust, and S. Varki (1997). “Customer delight: Foundations, findings, and managerial insight.” Journal of Retailing, 73 (3): 311-36.

Petrick, J. F. (2004). “Are loyal visitors desired visitors?” Tourism Management, 25 (4): 46370. 
Podasakoff, P.M., S.B. MacKenzie, and J.-Y. Lee (2003). “Common Method Biases in Behavioral Research: A critical review of the literature and recommended remedies,” Journal of Applied Psychology, 88 (5): 879-896.

Reichheld, F. F. (1993). “Loyalty-Based Management.” Harvard Business Review, 71 (2): $64-73$.

Rust, R. T., and R. L. Oliver (1994). Service Quality: New Directions in Theory and Practice. London: Sage.

Schmidt, F. L., I. S. Oh, and T. L. Hayes (2009). "Fixed versus random effects models in meta analysis: Model properties and an empirical comparison of differences in results.” British Journal of Mathematical and Statistical Psychology, 62: 97-128.

Seiders, K., G.B. Voss, D. Grewal, and A.L. Godfrey (2005). “Do Satisfied Customers Really Buy More?” Journal of Marketing, 69 (10): 26-43.

Sharma, R., and P. Yetton (2001). “An Evaluation of a Major Validity Threat to the Technology Acceptance Model.” In: Ninth European Conference on Information Systems, edited by S. Smithson, J. Gricar, M. Podlogar, and S. Avgerinou. Bled, Slovenia. pp.1170-5.

Sharma, R., and P. Yetton (2003). “The Contingent Effects of Management Support and Task Interdependence on Successful Information Systems Implementation.” MIS Quarterly, 27: 533-56. 
Sharma, R., and P. Yetton (2007). “The Contingent Effects of Training, Technical Complexity and Task Interdependence on Successful Information Systems Implementation.” MIS Quarterly, 31: 219-38.

Sharma, R., and P. Yetton (2011). “Top Management Support and IS Implementation: Further Support for the Moderating Role of Task Interdependence.” European Journal of Information Systems, 20: 703-12.

Sharma, R., P. Yetton, and J. Crawford (2007). “Common Methods Bias: Reports of its Demise are Highly Exaggerated.” In International Conference on Information Systems. Montreal: Association for Information Systems. pp. 32-4

Sharma, R., P. Yetton, and J. Crawford (2009). "Estimating the Effect of Common Method Variance: The Method-Method Pair Technique with an Illustration from TAM Research.” MIS Quarterly, 33: 473-90.

Soderlund, M., and N. Ohman (2003). "Behavioral intentions in satisfaction research revisited.” Journal of Consumer Satisfaction, Dissatisfaction and Complaining Behavior, 16: 53-66.

Spreng, R. A., S. B. Mackenzie, and R. W. Olshavsky (1996). “A reexamination of the determinants of consumer satisfaction.” Journal of Marketing, 60 (3): 15-32.

Swan, J. E., and R. L. Oliver (1989). "Postpurchase communications by consumers.” Journal of Retailing, 65 (4): 516-33.

Voss, G.B., A. Godfrey, and K. Seiders (2010). “How Complementary and Substitution Alter the Customer Satisfaction-Repurchase Link.” Journal of Marketing, 74 (11): 111-27. 
Weaver, P. A., K. Weber, and K. W. McCleary (2007). "Destination Evaluation: The Role of Previous Travel Experience and Trip Characteristics.” Journal of Travel Research, 45 (3): 333-44.

Westbrook, R. A., and R. L. Oliver (1991). “The Dimensionality of Consumption Emotion Patterns and Consumer Satisfaction.” Journal of Consumer Research, 18 (1): 84-91.

Williams, P., and G. N. Soutar (2009). "Value, satisfaction and behavioral intentions in an adventure tourism context.” Annals of Tourism Research, 36 (3): 413-38.

Wolf, F. M. (1986). Meta-Analysis: Quantitative Methods for Research Synthesis. Beverly Hills, CA: Sage.

Yi, Y. (1990). “A Critical Review of Consumer Satisfaction.” In Review of Marketing, Vol. 4. edited by V. A. Zeithaml. Chicago, Il.: America Marketing Association. pp. 68-123.

Yuan, J., and S. Jang (2007). “The Effects of Quality and Satisfaction on Awareness and Behavioral Intentions: Exploring the Role of a Wine Festival.” Journal of Travel Research, 46 (3): 279-88.

Zeithaml, V. A., L. L. Berry, and A. Parasuraman (1996). “The behavioral consequences of service quality.” Journal of Marketing, 60 (2): 31-46. 


\section{Tables}

Table 1. Satisfaction and intention to return to the same destination

\begin{tabular}{|c|c|c|c|c|}
\hline & & & rall, the vacati & \\
\hline & & & met my & \\
\hline & & was better than & expectations & did not meet my \\
\hline & & expected (\%) & (\%) & expectations (\%) \\
\hline & Almost certain & 24 & 30 & 14 \\
\hline $\begin{array}{l}\text { Intention to return to } \\
\text { destinations }\end{array}$ & Probably & 35 & 32 & 19 \\
\hline & Unlikely & 41 & 39 & 67 \\
\hline
\end{tabular}

Source: Austrian Guest Survey Data, Summer 1994.

Notes: $\mathrm{n}=7,967$, chi-square test $\mathrm{p}$-value $<0.000$. 
Table 2: Coefficients of binary logistic regression predicting intention to return to the destination (Austrian Guest Survey Data, Summer 1994, $n=7967$, Chi-squared 751, 22 df, $p<0.000$, Cox and Snell $=0.182$, Nagelkerke R squared $=0.243)$, significant variables shaded grey

\begin{tabular}{|c|c|c|c|c|c|c|}
\hline & B & S.E. & Wald & df & Sig. & $\operatorname{Exp}(B)$ \\
\hline VISITED DESTINATION BEFORE & 0.918 & 0.041 & 495.004 & 1 & 0.000 & 2.504 \\
\hline TRAVEL MOTIVE: entertainment & 0.245 & 0.092 & 7.126 & 1 & 0.008 & 1.278 \\
\hline TRAVEL MOTIVE: culture & 0.241 & 0.076 & 9.987 & 1 & 0.002 & 1.273 \\
\hline TRAVEL MOTIVE: programs for kids & 0.164 & 0.119 & 1.906 & 1 & 0.167 & 1.179 \\
\hline TRAVEL MOTIVE: change of environment & 0.118 & 0.099 & 1.42 & 1 & 0.233 & 1.125 \\
\hline TRAVEL MOTIVE: creativity & 0.103 & 0.1 & 1.067 & 1 & 0.302 & 1.109 \\
\hline TRAVEL MOTIVE: romantic atmosphere & 0.087 & 0.08 & 1.176 & 1 & 0.278 & 1.091 \\
\hline TRAVEL MOTIVE: spoiling yourself & 0.053 & 0.079 & 0.459 & 1 & 0.498 & 1.055 \\
\hline TRAVEL MOTIVE: fun & 0.022 & 0.085 & 0.067 & 1 & 0.795 & 1.022 \\
\hline TRAVEL MOTIVE: protection of environment & 0.017 & 0.099 & 0.031 & 1 & 0.860 & 1.018 \\
\hline TRAVEL MOTIVE: everything organized & 0.008 & 0.091 & 0.007 & 1 & 0.933 & 1.008 \\
\hline TRAVEL MOTIVE: locals & -0.014 & 0.081 & 0.031 & 1 & 0.861 & 0.986 \\
\hline TRAVEL MOTIVE: adventure & -0.027 & 0.087 & 0.1 & 1 & 0.752 & 0.973 \\
\hline TRAVEL MOTIVE: nature & -0.046 & 0.107 & 0.185 & 1 & 0.667 & 0.955 \\
\hline TRAVEL MOTIVE: water and sun & -0.060 & 0.076 & 0.617 & 1 & 0.432 & 0.942 \\
\hline TRAVEL MOTIVE: unconstrained & -0.063 & 0.095 & 0.435 & 1 & 0.510 & 0.939 \\
\hline
\end{tabular}


TRAVEL MOTIVE: sport

SATISFACTION

TRAVEL MOTIVE: health and beauty

TRAVEL MOTIVE: socializing

TRAVEL MOTIVE: rest and relax

TRAVEL MOTIVE: coziness

Constant

Source: Austrian Guest Survey Data, Summer 1994

Significant variables are shaded in grey. $\begin{array}{llllll}-0.126 & 0.081 & 2.437 & 1 & 0.118 & 0.882\end{array}$

$\begin{array}{llllll}-0.152 & 0.083 & 3.411 & 1 & 0.065 & 0.859\end{array}$

$\begin{array}{llllll}-0.153 & 0.08 & 3.667 & 1 & 0.056 & 0.858\end{array}$

$\begin{array}{llllll}-0.198 & 0.08 & 6.191 & 1 & 0.013 & 0.82\end{array}$

$\begin{array}{llllll}-0.253 & 0.096 & 7.001 & 1 & 0.008 & 0.777\end{array}$

$\begin{array}{llllll}-0.426 & 0.086 & 24.449 & 1 & 0.000 & 0.653\end{array}$

$\begin{array}{llllll}-0.847 & 0.195 & 18.863 & 1 & 0.000 & 0.429\end{array}$

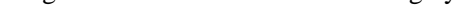


Table 3. Meta-analysis estimates of mean correlation between satisfaction and behavioral intention across studies

Model Number of data points Effect size and 95\% interval

Point estimate of Lower limit Upper limit
correlation

Fixed effect

38

0.63

0.62

0.63

Random effects

38

0.59

0.51

0.65 
Table 4. Test of between-study heterogeneity

Q-value $\quad d f(Q) \quad$ P-value I squared Tau squared $\quad$ Tau

$\begin{array}{llllll}2,094.4 & 37 & 0.00 & 98.2 & 0.11 & 0.33\end{array}$


Table 5. Test of type of dependent variable as moderator

$\begin{array}{lccc}\begin{array}{l}\text { IV type } \\ \text { studies }\end{array} & \begin{array}{c}\text { Mean correlation across studies } \\ (95 \% \mathrm{Cl})\end{array} & \text { Significance } \\ 1=\text { Intention } & 23 & 0.53(0.42-0.62) & \\ 2=\text { Loyalty } & 11 & 0.67(0.54-0.76) & \mathrm{p}=0.16 \text { (NS) } \\ 3 \text { = Others } & 4 & 0.67(0.44-0.82) & \end{array}$


Table 6. Test of type of independent variable as moderator

$\begin{array}{lccc}\text { IV type } & \begin{array}{c}\text { Number of } \\ \text { studies }\end{array} & \begin{array}{c}\text { Mean correlation across studies } \\ (95 \% \mathrm{Cl})\end{array} & \text { Significance } \\ 1 \text { = Satisfaction } & 21 & 0.61(0.51-0.69) & \mathrm{p}=0.51 \text { (ns) } \\ 2 \text { = Others } & 17 & 0.56(0.44-0.66) & \end{array}$


Table 7. Items employed in operationalization of the dependent variable

Number of times item is included in operationalization

$\begin{array}{lcccc}\text { DV label } & \text { Word of mouth } & \begin{array}{c}\text { Purchase } \\ \text { intention }\end{array} & \text { Price sensitivity } & \text { Others } \\ \text { Intention } & 9 & 21 & 1 & 2 \\ \text { Loyalty } & 8 & 10 & 0 & 0\end{array}$


Table 8. Items employed in operationalizations of the independent variable

Number of times item is included in operationalization

DV label

Satisfaction

$$
\text { Expectation- }
$$

performance gap

3

Decision

quality

Satisfaction

Other 


\section{Figures}

Figure 1. The many measures of satisfaction in tourism

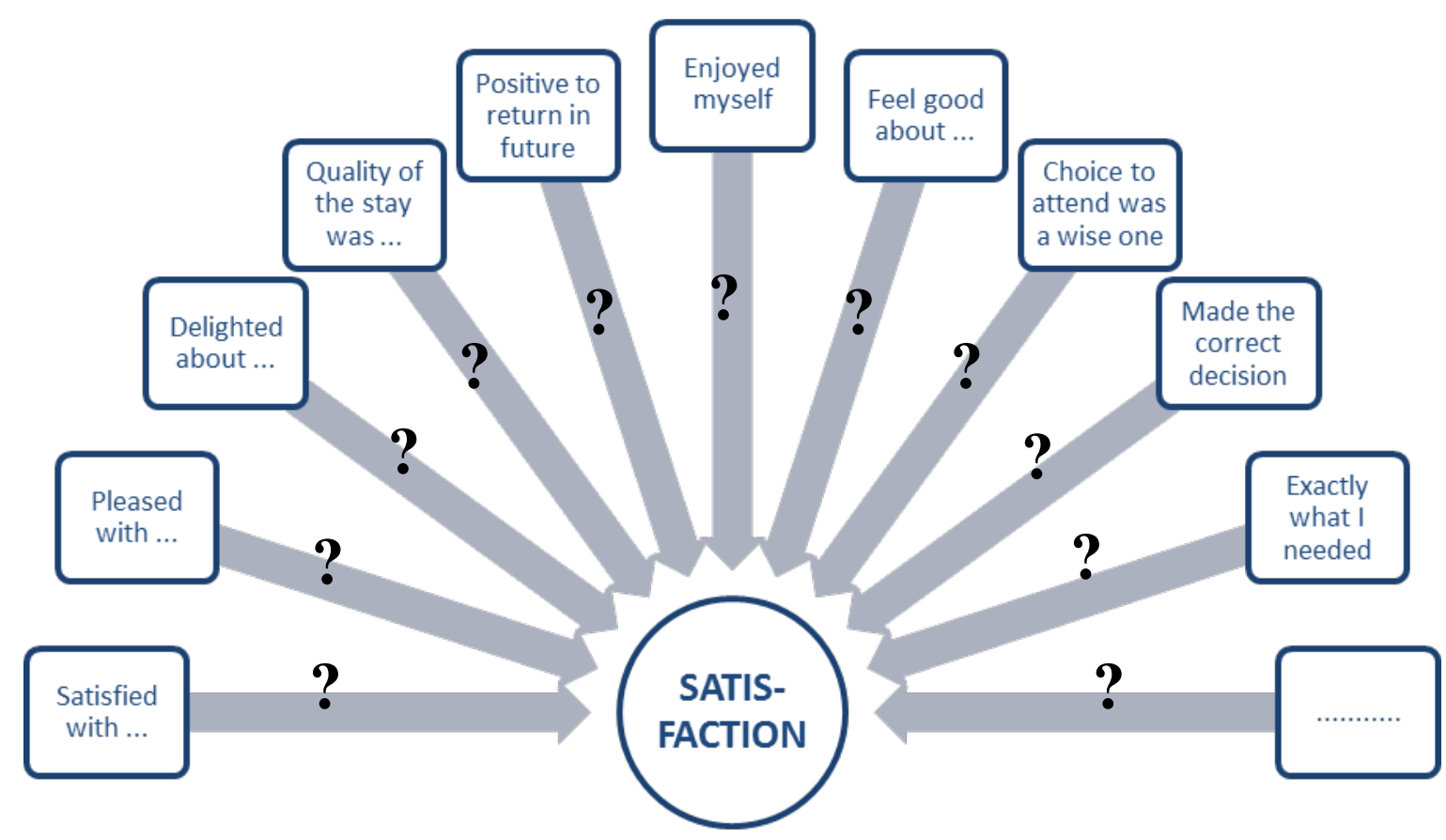

